\title{
An Accurate Virtual Signal Injection Control of MTPA for IPMSM with Fast Dynamic Response
}

\author{
J. Wang ${ }^{1}$ Student Member, IEEE, X. Y. Huang ${ }^{1}$ Member, IEEE, D. Yu ${ }^{1}$, Y. Z. Chen ${ }^{1}$, J. Zhang*1, F. \\ $\mathrm{Niu}^{1}$ Member, IEEE, Y. T. Fang ${ }^{1}$ Member, IEEE, W. Cao ${ }^{2}$ Senior Member, IEEE and H. Zhang ${ }^{3}$ Member, IEEE \\ ${ }^{1}$ College of Electrical Engineering, Zhejiang University, Hangzhou, China, 310027 \\ ${ }^{2}$ School of Engineering and Applied Science, Aston University, Birmingham, UK, B47ET \\ ${ }^{3}$ University of Nottingham Ningbo China, Ningbo, China \\ *Emails: jian_zhang_zju@zju.edu.cn
}

\begin{abstract}
A maximum torque per ampere (MTPA) control based on virtual signal injection for interior permanent magnet synchronous motor (IPMSM) with fast dynamic response is proposed in this paper. A small square wave signal is mathematically injected into current angle for accurately tracking MTPA points. The extracted derivative of elctromagnetic torque is utilized to compensate the initially set current angle to the real MTPA operation current angle. Due to the absence of bandpass and lowpass filters which are essential in the sinusoidal injected signal scheme, this method shows good dynamic response. By incorporating a modified equation for the torque after signal injection, the steady-state accuracy is also enhanced. The dand q-axes current references are obtained through the current vector magnitude and optimal current angle instead of using the torque equation with nominal motor parameters, which guarantees the accuracy of the output torque. The proposed scheme is parameter independent and no real signal is injected to the current or voltage command. Thus, the problems of highfrequency signal injection method are avoided. A prototype is set up and experiments are carried out to verify effectiveness and robustness of the proposed control scheme.
\end{abstract}

Index Terms-Interior permanent magnet synchronous motor (IPMSM), virtual signal injection, maximum torque per ampere (MTPA).

\section{INTRODUCTION}

The interior permanent magnet synchronous motors (IPMSM) are widely used in various applications due to its merits such as high power/torque density, high efficiency, high power factor and robustness over other ac motors, and excellent field-weakening performance [1], [2]. To fully utilize the reluctance torque of IPMSM, maximum torque per ampere (MTPA) operation is preferred and it can be realized by controlling the current angle using the motor parameters under a certain stator current [3]. However, the parameters of IPMSM exhibit obvious nonlinear characteristics due to magnetic saturation, cross-coupling effect and temperature dependence. Thus, the perfect MTPA points tracking in practical applications is usually difficult.

The MTPA points are usually calculated using constant nominal parameters [3], [4]. However, the d-, q-axes inductances and permanent flux linkage may decrease dramatically due to the magnetic saturation, which severely deteriorates the accuracy of MTPA points tracking [5], [6]. Various methods have been presented to deal with this problem and they can be classified into two categories: the offline ones and online ones.

For the offline procedures, the d-, q-axes current references for MTPA points considering parameter variations are usually obtained from look-up table (LUT), which is generated based on offline experiments or finite element method (FEM) simulations [7]-[9]. For an accurate control, both of magnetic saturation and demagnetization should be considered, and hence, massive experiments or simulations have to be carried out, which is time-consuming. In [10], a simpler LUT is set up at the cost of a relatively complicated control scheme. The d-, q-axes current references are updated based on the LUT each iteration until they converge to certain values. However, such an iteration algorithm may lead to a convergence problem.

For the online methods, it can be basically divided into two categories, the online parameter estimation and virtual signal injection. To deal with the parameter variation problem, one typical solution is estimating the real-time parameters and different estimation algorithms have been proposed, such as recursive least square (RLS) [11], [12] and affine projection algorithm (APA) [13], [14]. In [13], only q-axis inductance and permanent flux linkage are estimated to avoid the rank deficient problem, and the estimation algorithm is combined with a self-correction scheme to realize the real-time MTPA tracking. However, the variation of $\mathrm{d}$-axis inductance and resistance may deteriorate the tracking accuracy. In [11], [12], [14], additional signals are injected to estimate all four parameters, but additional copper loss is inevitable. A backstepping control scheme based on Lyapunov criterion was first proposed in [15] to realize the zero d-axis current control and the scheme is extended to MTPA control in [16]. This control scheme replaces the traditional PI controller by a backstepping controller with the parameters updated in each control period. However, the computation burden is heavy, which may result in stability issues. In recent years, some signal injection methods are proposed to track the real-time MTPA points [17][19]. These control schemes are parameter independent and the accuracy of the MTPA tracking is satisfactory. However, as mentioned before, the additional injected signal brings additional copper loss as well. 
A virtual signal injection method to track the MTPA operation points is proposed in [20]. A small sinusoidal signal is injected to the current angle and the torque derivative is obtained through various filters to generate the desired d-axis current. This control scheme can track the MTPA operation points, but the dynamic response is quite slow due to the use of overmuch filters and the steady-state error is unbearable. To improve the dynamic control performance, a self-learning controller based on virtual signal injection is proposed in [21]. The controller is trained online and operates well if the same operation condition has been trained before. However, the dynamic performance is still unsatisfactory when the operation conditions are firstly encountered and in practical applications, the operation condition, i.e., the torque command may vary in a such a large range that it is time-consumed to train every operation condition.

In this paper, a novel virtual signal injection method with fast dynamic response and accurate MTPA points tracking is proposed. A square injection signal removes the utilization of cascaded filters, which leads to a fast dynamic response. The method to obtain command stator current amplitude is discussed in detail for torque control. No real signal is injected to the motor, and hence, the problems associated with highfrequency signal injection methods are avoided. Based on the analysis of the characteristic of virtual signal injection method, the modified equation of electromagnetic torque considering signal injection is proposed to enhance the MTPA tracking accuracy. A simple compensation method is utilized to generate the current vector magnitude reference. The simulations and experiments are conducted on MATLAB/Simulink and a prototype IPMSM drive system with dSPACE to support the claims.

\section{System Model with InJected Signal}

The mathematical model of an IPMSM in synchronously rotating d-q frame can be expressed as:

$$
\begin{aligned}
v_{d} & =R_{s} i_{d}+p L_{d} i_{d}+e_{d} \\
v_{q} & =R_{s} i_{q}+p L_{q} i_{q}+e_{q} \\
e_{d} & =-\omega_{e} L_{q} i_{q} \\
e_{q} & =\omega_{e}\left(L_{d} i_{d}+\psi_{f}\right) \\
T_{e} & =\frac{3}{2} \frac{P}{2}\left[\psi_{f} i_{q}+\left(L_{d}-L_{q}\right) i_{d} i_{q}\right]
\end{aligned}
$$

where $v_{d}$ and $v_{q}$ are the synthesized voltages in d-q frame applying to the motor terminal from PWM inverter; $i_{d}$ and $i_{q}$ are the currents in d-q frame; $R_{s}, L_{d}$ and $L_{q}$ represent the stator resistance, $\mathrm{d}$-axis stator inductance and q-axis stator inductance, respectively; $e_{d}$ and $e_{q}$ denote the effective backEMFs of d- and q-axes; $\omega_{e}$ and $\psi_{f}$ are electrical angular velocity and stator flux linkage of permanent magnet; $p$ is the differential symbol and $P$ represents the number of poles.

The electromagnetic torque is consisted of two parts, i.e., the interaction of permanent magnet flux linkage with q-axis current and the reluctance torque due to the rotor saliency. For a given magnitude of the current vector, the torque equation can be rewritten as a function of current angle:

$$
T_{e}(\beta)=\frac{3}{2} \frac{P}{2}\left[\psi_{f} I_{s} \cos \beta-\frac{1}{2}\left(L_{d}-L_{q}\right) I_{s}^{2} \sin 2 \beta\right]
$$

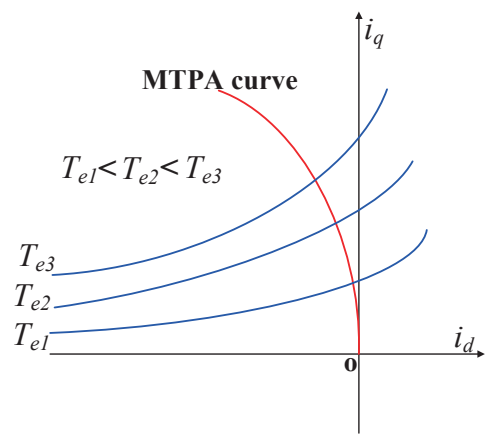

Fig. 1. MTPA and constant torque curves

where $I_{s}$ is the magnitude of current vector and $\beta$ is the current angle between current vector and q-axis. The MTPA operation points are the points on the constant torque curves which have the minimum stator current magnitude. As can been seen in Fig. 1, the MTPA locus is vertical to the constant torque curve and the optimal current angle $\beta$ for MTPA control can be derived by setting $\partial T_{e} / \partial \beta$ to zero [22]:

$$
\beta=\sin ^{-1} \frac{-\psi_{f}+\sqrt{\psi_{f}^{2}+8\left(L_{q}-L_{d}\right)^{2} I_{s}^{2}}}{4\left(L_{q}-L_{d}\right) I_{s}}
$$

Theoretically speaking, if the current angle is kept consistent with the result of equation (3) during the operation, the motor can track the MTPA operation points. However, $L_{d}$ and $L_{q}$ vary from the nominal values due to the magnetic saturation and $\psi_{f}$ may decrease greatly as the temperature gets higher. Hence, the optimal current angle deviates seriously from the calculated one of equation (3) using nominal values of motor parameters, which leads to the poor MTPA tracking.

The relationship bewteen current angle and torque with a fixed current vector magnitude is illustrated in Fig. 2. It is evident $\partial T_{e} / \partial \beta$ is positive when current angle is smaller than the optimal one, and is negative when current angle is greater than the optimal one. According to this feature, a small signal can be injected into the current angle to obtain the value of $\partial T_{e} / \partial \beta$ and then the MTPA operation points can be accurately tracked according to the value of $\partial T_{e} / \partial \beta$.

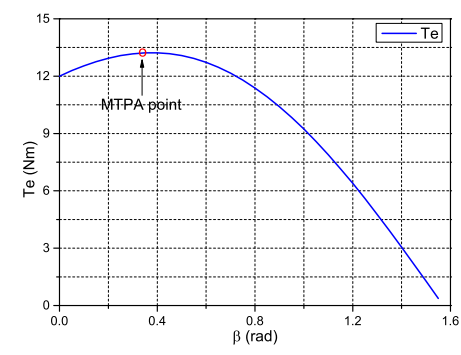

Fig. 2. Relationship between current angle and torque under fixed current vector magnitude

In this work, a $50 \%$ duty cycle square wave expressed by (4) is utilized as the injection angle variation where $T_{s}$ represents 
the signal period, $A$ is the amplitude of the injection signal and $N$ denotes the nature number set.

$$
\gamma(t)=\left\{\begin{array}{lr}
0 & N T_{s} \leqslant t<\left(N+\frac{1}{2}\right) T_{s} \\
A & \left(N+\frac{1}{2}\right) T_{s} \leqslant t<(N+1) T_{s}
\end{array}\right.
$$

Combining (2) and (4) gives:

$T_{e}^{h}(\gamma)=\frac{3}{2} \frac{P}{2}\left[\psi_{f} I_{s} \cos (\beta+\gamma)-\frac{1}{2}\left(L_{d}-L_{q}\right) I_{s}^{2} \sin 2(\beta+\gamma)\right]$

where $T_{e}^{h}$ represents the electromagnetic torque after signal injection.

\section{Proposed Virtual Signal Injection Method}

\section{A. Current angle compensation}

Assume that (5) is a function of $\gamma$ and use Taylor's series expansion around origin yields

$$
\begin{aligned}
T_{e}^{h}(\gamma) & =T_{e}^{h}(0)+\left.\frac{\partial T_{e}^{h}}{\partial \gamma}\right|_{\gamma=0} \gamma+\left.\frac{1}{2} \frac{\partial^{2} T_{e}^{h}}{\partial^{2} \gamma}\right|_{\gamma=0} \gamma^{2}+\cdots \\
& =T_{e}(\beta)+\frac{\partial T_{e}}{\partial \beta} \gamma+\frac{1}{2} \frac{\partial^{2} T_{e}}{\partial^{2} \beta} \gamma^{2}+\cdots
\end{aligned}
$$

Because the amplitude of injection signal $A$ is quite small, the first-order term in equation (6) is dominant in torque variation compared with the other high-order components. Thus, the Taylor's series can be truncated after the first-order term:

$$
T_{e}^{h}(\gamma)=T_{e}(\beta)+\frac{\partial T_{e}}{\partial \beta} \gamma
$$

In equation (7), $T_{e}(\beta)$ indicates the torque without injection signal, i.e., the electromagnetic torque of the motor. It can be calculated using (1). But as mentioned before, the motor parameters may deviate from its nominal values greatly, so the torque can be calculated using the mechanical power. The mechanical power without iron loss considered can be expressed as:

$$
P_{m}=\frac{3}{2}\left[\left(v_{d}-R i_{d}\right) i_{d}+\left(v_{q}-R i_{q}\right) i_{q}\right]
$$

As an alternative, $T_{e}(\beta)$ can be obtained from:

$$
\begin{aligned}
T_{e}(\beta) & =\frac{P_{m}}{\omega_{m}}=\frac{3}{2 \omega_{m}}\left[\left(v_{d}-R i_{d}\right) i_{d}+\left(v_{q}-R i_{q}\right) i_{q}\right] \\
& =\frac{3}{2 \omega_{m}}\left[-\left(v_{d}+R I_{s} \sin \beta\right) I_{s} \sin \beta+\left(v_{q}-R I_{s} \cos \beta\right) I_{s} \cos \right.
\end{aligned}
$$

where $\omega_{m}$ represents the mechanical angular velocity and satisfies the relationship $\omega_{e}=\frac{P}{2} \omega_{m}$.

In [20], the electromagnetic torque after signal injection is calculated by:

$$
T_{e}^{h}=\frac{3}{2}\left[\frac{v_{q}-R i_{q}}{\omega_{m}}+\frac{v_{d}-R i_{d}}{i_{q} \omega_{m}} i_{d}^{h}\right] i_{q}^{h}
$$

where $i_{d}^{h}$ and $i_{q}^{h}$ represent the d- and q-axes current after signal injection, respectively. However, the accuracy of results obtained from this equation is intolerable.
The electromagnetic torque after signal injection can be accurately calculated by:

$$
\begin{aligned}
T_{e}^{h} & =\frac{3}{2} \frac{P}{2}\left[\psi_{f} i_{q}^{h}+\left(L_{d}-L_{q}\right) i_{d}^{h} i_{q}^{h}\right] \\
& =\frac{3}{2} \frac{P}{2}\left[\psi_{f} i_{q}^{h}+L_{d} i_{d}^{h} i_{q}^{h}-L_{q} i_{d}^{h} i_{q}^{h}\right]
\end{aligned}
$$

However, the accuracy of (11) depends heavily on the accurate knowledge of motor parameters which deviates from their nominal values during the operation. Thus, equation (10) should be modified to approach the value obtained by equation (11).

In steady-state operation, the voltage equation can be rewritten as:

$$
\begin{gathered}
v_{d}-R i_{d}=-\omega_{e} L_{q} i_{q} \\
v_{q}-R i_{q}=\omega_{e} \psi_{f}+\omega_{e} L_{d} i_{d}
\end{gathered}
$$

The third term in the bracket of (11) can be easily obtained through (12)

$$
\frac{v_{d}-R i_{d}}{\omega_{e} i_{q}} i_{d}^{h} i_{q}^{h}=-L_{q} i_{d}^{h} i_{q}^{h}
$$

From (13) the first two terms in the bracket of (11) can be calculated by

$$
\begin{aligned}
\psi_{f} i_{q}^{h}+L_{d} i_{d}^{h} i_{q}^{h} & =\left(\psi_{f}+L_{d} i_{d}\right) i_{q}^{h}+L_{d} i_{q}^{h}\left(i_{d}^{h}-i_{d}\right) \\
& =\frac{v_{q}-R i_{q}}{\omega_{e}} i_{q}^{h}+L_{d} i_{q}^{h}\left(i_{d}^{h}-i_{d}\right)
\end{aligned}
$$

As the amplitude of the injected signal $\gamma$ is vary small, $i_{d}^{h}$ can be expressed as:

$i_{d}^{h}=-I_{s} \sin (\beta+\gamma) \approx-I_{s} \sin \beta-\gamma I_{s} \cos \beta=i_{d}-i_{q} \gamma$

Substituting (16) into (15) yields:

$$
\psi_{f} i_{q}^{h}+L_{d} i_{d}^{h} i_{q}^{h}=\left(\frac{v_{q}-R i_{q}}{\omega_{e}}-L_{d} i_{q} \gamma\right) i_{q}^{h}
$$

Hence, $T_{e}^{h}$ can be expressed as:

$T_{e}^{h}(\gamma)=\frac{3}{2 \omega_{m}}\left[\frac{v_{d}-R i_{d}}{i_{q}} i_{d}^{h} i_{q}^{h}+\left(v_{q}-R i_{q}-\omega_{e} L_{d} i_{q} \gamma\right) i_{q}^{h}\right]$

The $\mathrm{d}$-axis inductance may deviate from its nominal value due to magnetic saturation. However, compared to q-axis inductance, the variation of $\mathrm{d}$-axis inductance is smaller because the flux in d-axis is intense and the d-axis is somewhat saturated under no load condition. In addition, the small amplitude of $\gamma$ also reduces the impacts of varied d-axis inductance.

The value of $\gamma \partial T_{e} / \partial \beta$ can be obtained by combining (4), (7), (9) and (18) and into :

$$
\frac{\partial T_{e}}{\partial \beta} \gamma(t)=\left\{\begin{array}{lr}
0 & N T_{s} \leqslant t<\left(N+\frac{1}{2}\right) T_{s} \\
\frac{\partial T_{e}}{\partial \beta} A & \left(N+\frac{1}{2}\right) T_{s} \leqslant t<(N+1) T_{s}
\end{array}\right.
$$

The maximum value of (19) is extracted and updated in each control cycle. Utilizing a pure integral, the current angle compensation value is added to an initial current angle to track the optimal current angle. The schematic diagram of the signal processing technique is illustrated in Fig. 3. 


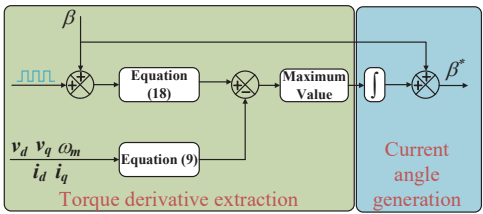

Fig. 3. Schematic of signal processing technique

\section{B. Current vector magnitude generation}

The current vector magnitude is also a key factor as it determines the maximum output torque. In some applications, the purpose of control system is to generate the desired torque rather than keeping the speed constant, and hence, the input command of motor control system is the torque reference. The ideal relationship between torque and current vector magnitude for a permanent magnet motor is linear

$$
T_{e}=K_{t} I_{s}
$$

where $K_{t}$ is the constant torque coefficient in ideal condition. However, the motor parameters may vary according to the operating condition, so that the torque coefficient cannot remain constant in practical applications. Thus, a classical open loop approach in parallel to closed loop approach based on an integral controller is utilized to compensate the current vector magnitude shown as equation (21)

$$
I_{s}=\frac{T_{e}^{*}}{K_{t}}+\frac{K_{t i}\left(T_{e}^{*}-T_{e}\right)}{s}
$$

where $T_{e}^{*}$ and $T_{e}$ are the torque reference and output torque calculated by (9), respectively and $K_{t i}$ represents the integrator coefficient. The scheme of current vector magnitude generation in torque mode is given in Fig. 4.

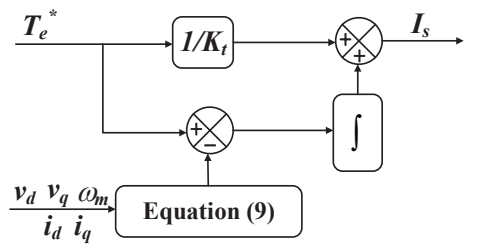

Fig. 4. Current vector magnitude generation in torque mode

\section{Control system}

The optimal angle and magnitude of current vector can be obtained through the aforementioned method and the d- and q-axes current references can be expressed as

$$
\begin{aligned}
& i_{d}^{*}=-I_{s} \sin \beta^{*} \\
& i_{q}^{*}=I_{s} \cos \beta^{*}
\end{aligned}
$$

Thus, the current references in (22) can accurately represent the actual MTPA points and proportional-integral (PI) controller is utilized to force the real currents to track the references. The control system is illustrated in Fig. 5. The detailed schematic of current angle and vector magnitude generator are the ones illustrated in Fig. 3 and Fig. 4.

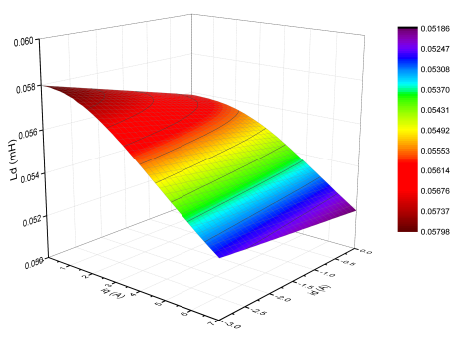

(a) d-axis inductance as a function of d-q axes currents

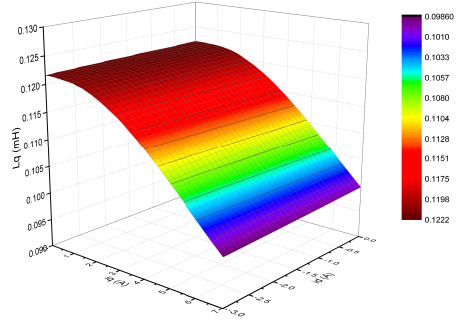

(b) q-axis inductance as a function of d-q axes currents

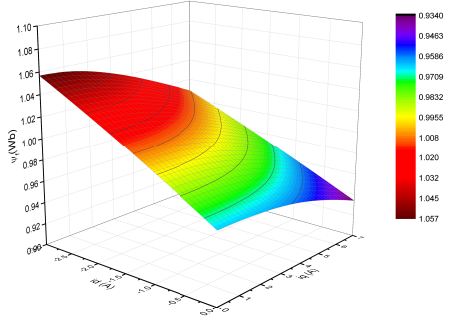

(c) Permanent magnet flux linkage as a function of $\mathrm{d}-\mathrm{q}$ axes currents

Fig. 6. Nonlinear IPMSM motor parameters

\section{Simulation Results}

Simulation based on MATLAB/Simulink is carried out to validate the effectiveness of proposed virtual signal injection control. Nominal parameters of the IPMSM are given in Table I. The inverter switching frequency is $5 \mathrm{kHz}$ and the frequency of injection square wave is $1 \mathrm{kHz}$, i.e., the signal period $T_{s}$ is $1 \mathrm{~ms}$. The PI current controller is designed with zero pole elimination principle and the bandwidth is set to $200 \mathrm{~Hz}$.

The inductances and permanent magnet flux linkage of the IPMSM under different load conditions are obtained using FEM as illustrated in Fig. 6. Obviously, the variation of inductance in $\mathrm{q}$-axis is severe than that of $\mathrm{d}$-axis and due to the variation of d-axis inductance, $\mathrm{q}$-axis inductance and permanent magnet flux linkage, and the MTPA points may deviate from the points obtained with nominal values.

To demonstrate the fast dynamic response of proposed method, the IPMSM simulations in torque mode with the speed held at 300rpm during the whole operation are carried out and the sinusoidal signal injection method in [20] is taken as a comparison. The torque command changes abruptly from 5 to $10 \mathrm{Nm}$ at $1.0 \mathrm{~s}$ and the $\mathrm{d}$ - and q-axes currents are illustrated 


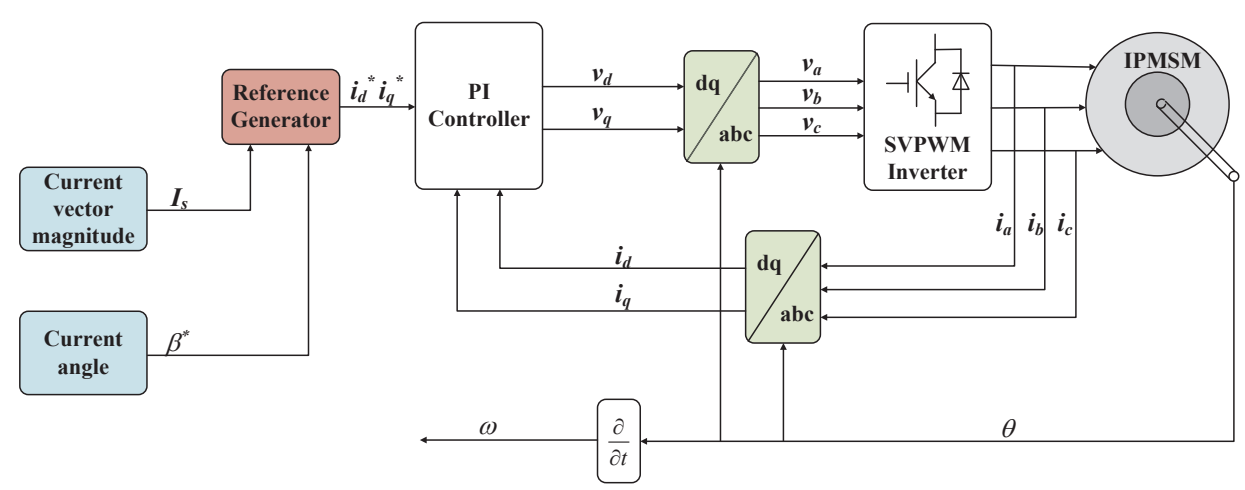

Fig. 5. Control system diagram

TABLE I

PARAMETERS OF THE TESTED IPMSM

\begin{tabular}{|c|c|}
\hline$P$ & 4 \\
\hline$R_{s}$ & $4.31 \Omega$ \\
\hline$\psi_{f}$ & $0.936 \mathrm{~Wb}$ \\
\hline$L_{d}$ & $56 \mathrm{mH}$ \\
\hline$L_{q}$ & $119 \mathrm{mH}$ \\
\hline$V_{D C}$ & $300 \mathrm{~V}$ \\
\hline$I_{s, \text { max }}$ & $8 \mathrm{~A}$ \\
\hline$P_{\text {rated }}$ & $2 \mathrm{~kW}$ \\
\hline$n_{\text {rated }}$ & $800 \mathrm{rpm}$ \\
\hline
\end{tabular}

in Fig. 7.

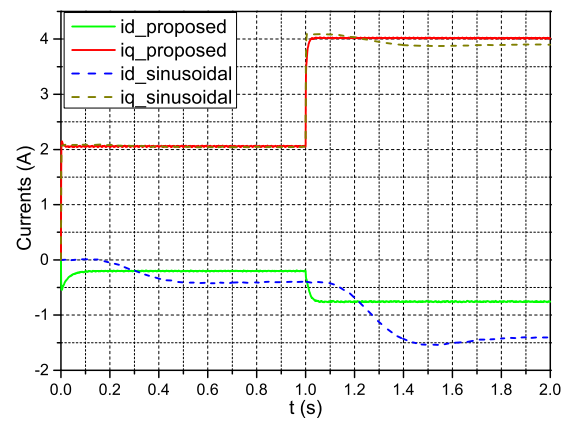

Fig. 7. Dynamic performances of the proposed method and the sinusoidal injection

As mentioned before, the cascaded filters in [20] severely deteriorate the dynamic performance and it takes $0.7 \mathrm{~s}$ for the motor to come into steady mode. The proposed method, however, shows a better dynamic performance with only $0.05 \mathrm{~s}$ transient process. It is also obvious that the two methods converge to different operation points. This difference comes from the different calculation methods of $T_{e}^{h}$ and the accuracy of the two methods is given in Fig. 8.

In Fig. 8, the blue curve is the MTPA operating line obtained using the FEM results in Fig. 6. As can been seen, the sinusoidal signal injection method deviates a lot from the MTPA line due to the inappropriate calculation of $T_{e}^{h}$ and the points obtained by (18) reveal better accuracy.

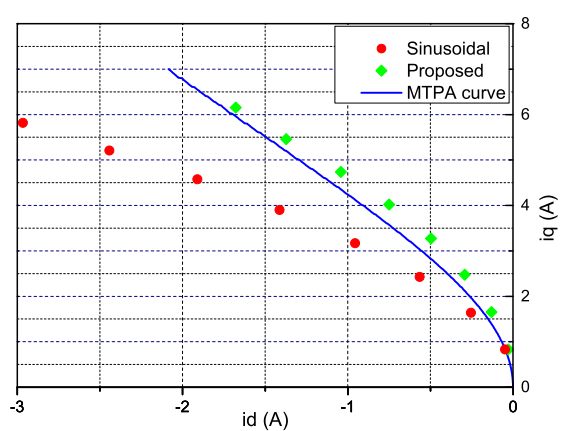

Fig. 8. The tracking accuracy of proposed method and sinusoidal signal injection method

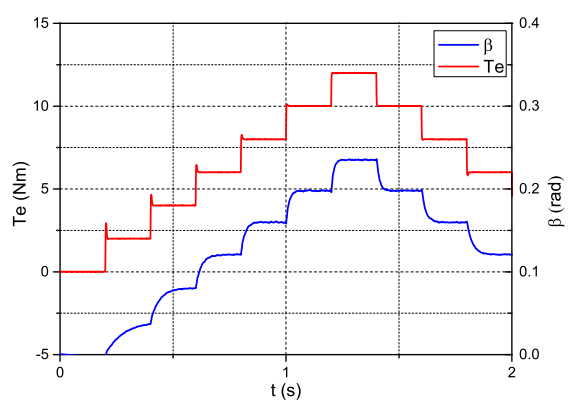

Fig. 9. Electromagnetic torque and current angle

Another simulation is carried out to verify the robustness of proposed method. The motor is running in torque mode at the speed of $800 \mathrm{rpm}$ and the torque command increases or decreases $2 \mathrm{Nm}$ every $0.2 \mathrm{~s}$.

The output torque and current angle are illustrated in Fig. 9 and the $\mathrm{d}$ - and q-axes currents are given in Fig. 10. As clearly shown, the proposed method is robust with fast transient response. 


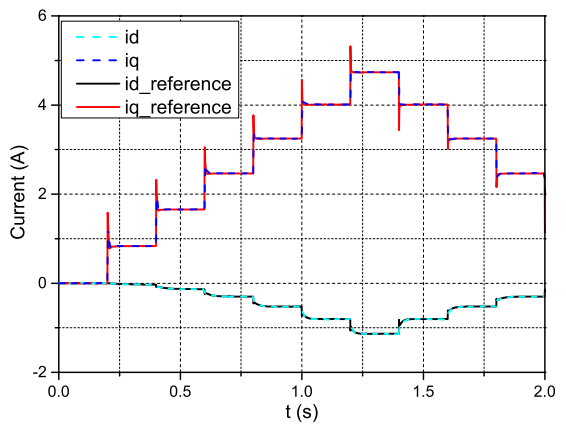

Fig. 10. d- and q-axes currents

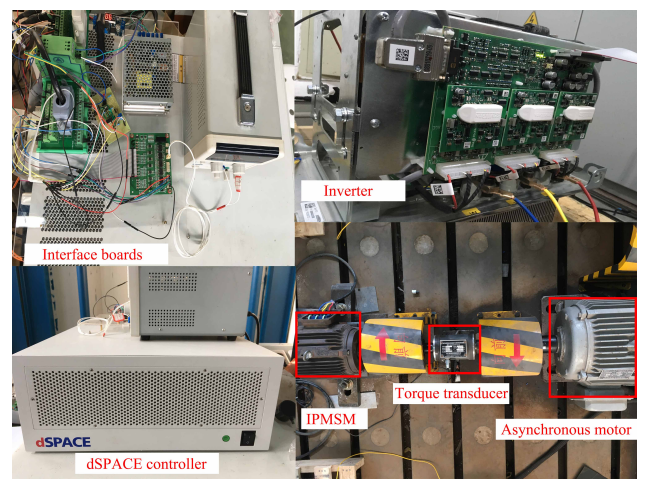

Fig. 11. Experimental setup

\section{EXPERIMENTAL RESULTS}

A test bench shown in Fig. 11 is set up to verify the proposed method and the motor parameters are the same as that given in Table I. The IPMSM is controlled in torque mode at a certain speed driven by the asynchronous motor and the motor torque is measured by a torque transducer JN338-A50. The controller's sampling rate is $5 \mathrm{kHz}$ and the carrier frequency is also $5 \mathrm{kHz}$. The frequency of injection signal has to be lower than the control frequency and it is selected as $1 \mathrm{kHz}$. The amplitude of the injected signal is $0.002 \mathrm{v}$.

The first set of tests is performed with the torque command varying from $1 \mathrm{Nm}$ to $20 \mathrm{Nm}$ in a step of $1 \mathrm{Nm}$ every 2 seconds at the speed of 300rpm. To demonstrate the accuracy of proposed method, the sinusoidal signal injection method proposed in [20] is still carried out as a comparison. Using the FEM results of $L_{d}, L_{q}$ and $\psi_{f}$, the MTPA curve is obtained by Newton-Raphson iteration method and the results are given in Fig. 12.

As can been clearly seen, the proposed method possesses a better MTPA tracking accuracy compared with the sinusoidal signal injection method which uses equation (10). The tracking MTPA points of proposed method do not exactly lie on the MTPA curve mainly due to the dead zone effect of inverter and the variation of d-axis inductance. The current vector magnitudes of proposed method and sinusoidal signal injection method are listed in Table II. The higher torque reference is, the larger current vector magnitude difference is.

To further demonstrate the accuracy of proposed method,

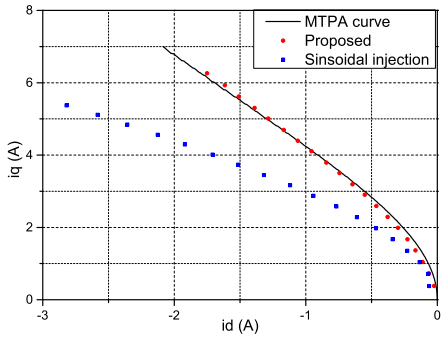

Fig. 12. The MTPA tracking experimental results at the speed of 300rpm

TABLE II

CURRENT VECTOR MAGNITUDE OF THE TWO METHODS

\begin{tabular}{cccc}
\hline $\begin{array}{c}\text { Torque } \\
\text { reference }\end{array}$ & $\begin{array}{c}\text { Current amplitude } \\
\text { of proposed method }\end{array}$ & $\begin{array}{c}\text { Current amplitude of } \\
\text { sinusoidal signal } \\
\text { injection method }\end{array}$ & $\begin{array}{c}\text { Current } \\
\text { amplitude } \\
\text { difference }\end{array}$ \\
\hline $1 \mathrm{Nm}$ & $0.392 \mathrm{~A}$ & $0.395 \mathrm{~A}$ & $0.0031 \mathrm{~A}$ \\
$5 \mathrm{Nm}$ & $1.72 \mathrm{~A}$ & $1.73 \mathrm{~A}$ & $0.01 \mathrm{~A}$ \\
$10 \mathrm{Nm}$ & $3.34 \mathrm{~A}$ & $3.38 \mathrm{~A}$ & $0.04 \mathrm{~A}$ \\
$15 \mathrm{Nm}$ & $4.98 \mathrm{~A}$ & $5.05 \mathrm{~A}$ & $0.07 \mathrm{~A}$ \\
$20 \mathrm{Nm}$ & $6.63 \mathrm{~A}$ & $6.74 \mathrm{~A}$ & $0.11 \mathrm{~A}$ \\
\hline
\end{tabular}

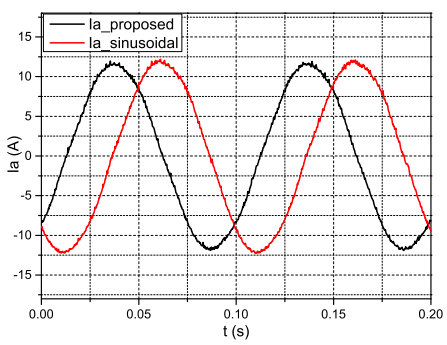

Fig. 13. Current waveform of phase A for the proposed method and sinusoidal injection method

Fig. 13 illustrates the current waveform of phase A of proposed method and sinusoidal signal injection method at the speed of $300 \mathrm{rpm}$ with $35 \mathrm{Nm}$ torque command. The root mean square value of $I_{a}$ for the two methods are $8.24 \mathrm{~A}$ and $8.51 \mathrm{~A}$, respectively. In other words, least current is needed under the same torque for proposed method and hence, a better MTPA tracking accuracy is achieved. As the torque gets higher, the current differences among the two methods will be larger.

The waveforms of $\mathrm{d}-\mathrm{q}$ axes currents and output torque, current angle are shown in Fig. 14(a) and Fig. 14(b), respectively. The extracted value of $\partial T_{e} / \partial \beta$ is utilized to generate the current angle rather than d-axis current reference through a integrator. Normally the current angle varies in a smaller range than that of d-axis current reference and the square wave injection signal removes the cascaded filter. Hence, the dynamic response of proposed method is better. Although the current angle may not converge to the steady value as fast as other variables, it quickly approaches the steady value and variations of the d-q axes current references are pretty small afterwards. The overshoots of output torque at each step are caused by the inappropriate torque coefficient and invalidity of equation (9) during fast transient, but with the help of 


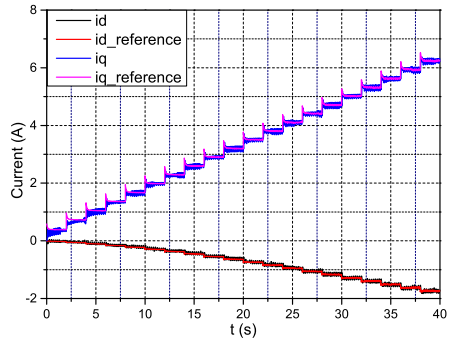

(a) Experimental results of $d-q$ axes currents at 300rpm

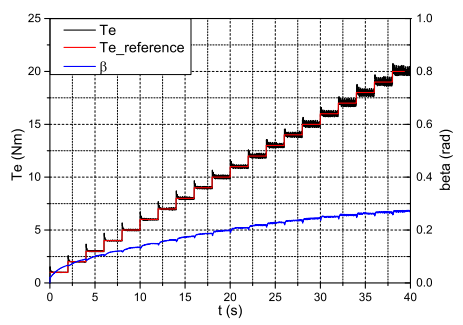

(b) Experimental results of output torque and current angle at 300rpm

Fig. 14. Measured results of the proposed method at 300rpm

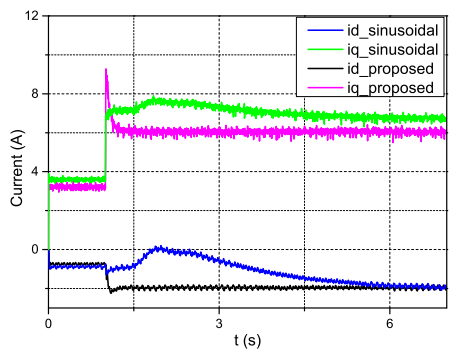

(a) Experimental comparisons of $\mathrm{d}-\mathrm{q}$ axes currents at 300rpm

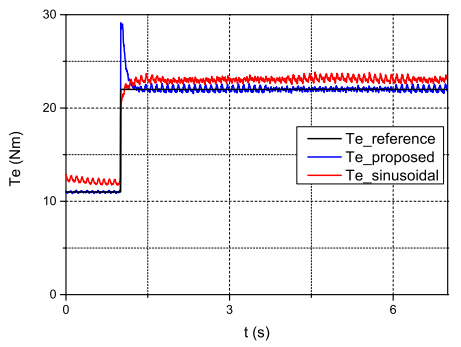

(b) Experimental comparisons of output torque at $300 \mathrm{rpm}$

Fig. 15. Experimental comparisons between proposed method and sinusoidal injection method

current vector magnitude generation using (21), the output torque quickly converges back to the torque command.

To prove the accurate output torque and fast dynamic response of the proposed scheme, the equation for $T_{e}^{h}$ in sinusoidal injection method is changed to equation (18) as well. The IPMSM is held at 300rpm with a step increase of torque reference from $11 \mathrm{Nm}$ to $22 \mathrm{Nm}$. The experimental results are illustrated in Fig. 15.

As can be seen in Fig. 15(a), the proposed method possesses obvious better dynamic response. The sinusoidal injection method utilizes torque derivative to generate d-axis current reference and the cascaded filters deteriorates the dynamics. Due to the variation of motor parameters, the q-axis current reference for the sinusoidal injection method is inappropriate, which leads to an inaccurate output torque as illustrated in Fig. 15(b).

The experiments of a medium speed of 600rpm are also carried out. The torque command varies in a step of $1 \mathrm{Nm}$ every 2 seconds and the experimental results are illustrated in Fig. 16. It is obviously seen that the proposed method can still track the MTPA points accurately with fast dynamic response at medium speed. The proposed MTPA tracking method keeps adjusting the current angle and current vector amplitude to track the real MTPA points and the torque responds quickly towards torque command. Obvious good accuracy can be achieved.

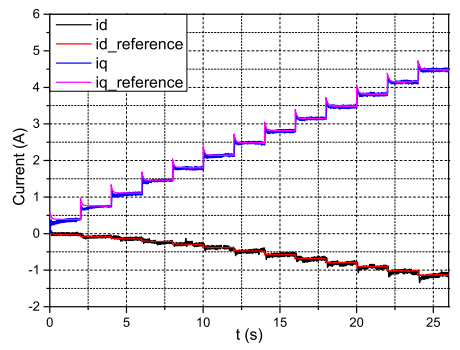

(a) Experimental results of d-q axes currents at $600 \mathrm{rpm}$

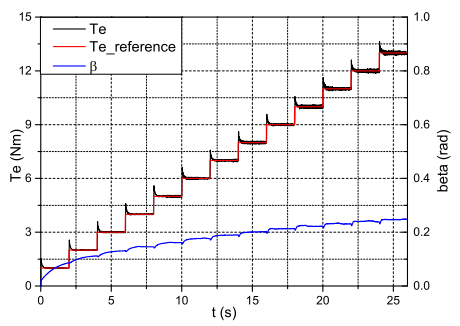

(b) Experimental results of output torque and current angle at 600rpm

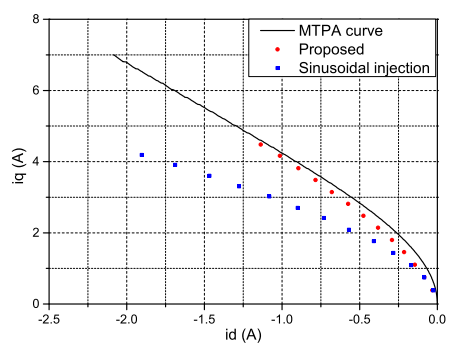

(c) Experimental results of the accuracy of the proposed method at 600rpm

Fig. 16. Measured results of the proposed method at 600rpm 
To thoroughly validate the robustness of the proposed method, the experiments of rated speed, i.e., 800rpm with continuous step decrease torque command are carried out. The torque command decreases $1 \mathrm{Nm}$ every 2 seconds and the experimental results are illustrated in Fig. 17.

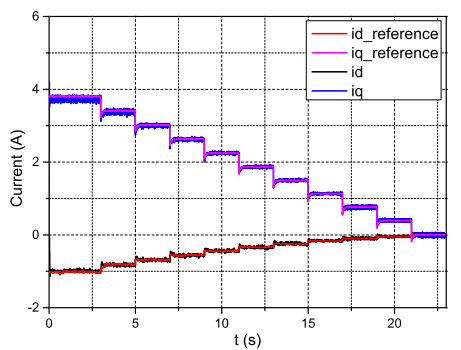

(a) Experimental results of $\mathrm{d}-\mathrm{q}$ axes currents at $800 \mathrm{rpm}$

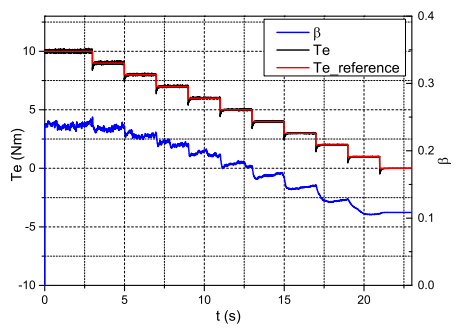

(b) Experimental results of output torque and current angle at $800 \mathrm{rpm}$

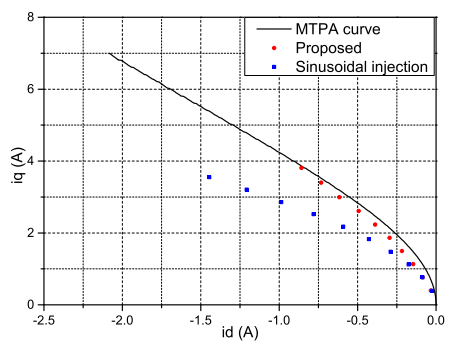

(c) Experimental results of the accuracy of the proposed method at $800 \mathrm{rpm}$

Fig. 17. Measured results of the proposed method at 800rpm

As the torque decreases, the initial current angle lies on the downhill side of Fig. 2 and the torque derivative is negative. Hence, The optimal current angle keeps decreasing. Good accuracy is still guaranteed under rated speed. The proposed MTPA tracking method shows good accuracy, dynamic response and robustness in a wide speed range under the rated speed.

To further demonstrated the dynamic process, another experiment under 800rpm with a step change of torque reference from $0 \mathrm{Nm}$ to $10 \mathrm{Nm}$ is illustrated in Fig. 18. As the torque reference increases, the current vector magnitude overshoots immediately as analyzed before and with the current angle remains unchanged, the torque derivative becomes positive. Thus, the optimal current angle keeps increasing and the torque derivative regresses back to zero. With the help of integrals, the current vector magnitude and optimal current angle converge to steady-state value. As the cascaded filters are removed, good dynamic response is achieved.

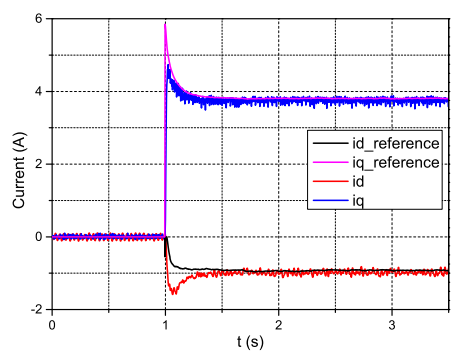

(a) Experimental results of d-q axes currents at $800 \mathrm{rpm}$ with step torque increase

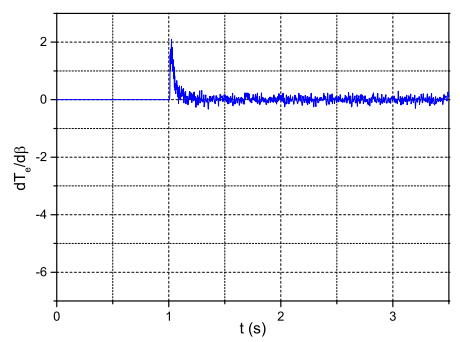

(b) Experimental results of torque derivative at $800 \mathrm{rpm}$ with step torque increase

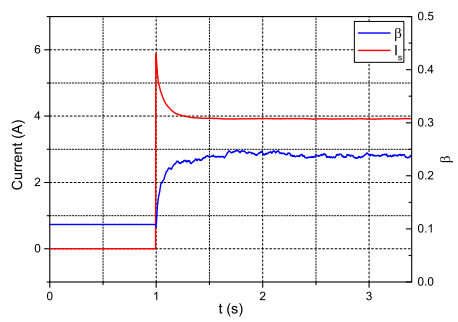

(c) Experimental results of current vector magnitude and optimal current angle at 800rp$\mathrm{m}$ with step torque increase

Fig. 18. Measured results of the proposed method at 800rpm with step torque increase

\section{CONCLUSION}

This paper proposes a novel virtual square wave signal injection method to track the real MTPA points accurately with fast dynamic response utilizing the fact that torque derivative to current angle equals zero at a MTPA point. Without various filters to extract the derivative of torque to current angle, the proposed method shows fast dynamic response and the derivative of torque to current angle is utilized to generate the current angle rather than d-axis current reference, which enhances the dynamic response as well. A more accurate equation of electromagnetic torque after signal injection guarantees the accuracy of MTPA tracking. The method to generate current vector magnitude for torque mode is illustrated. The $\mathrm{d}$ - and q-axes current references are obtained through current vector 
magnitude and optimal current angle without the utilization of variable motor parameters, which guarantees the accuracy of the output torque. The high-frequency signal is mathematically injected instead of injecting into current, and thus, the problems of traditional high-frequency signal injection method such as more copper losses, current and voltage harmonics sensitivity, can be avoided. Simulations and experiments are carried out, and the results demonstrate that the proposed control scheme can accurately track the MTPA points without accurate knowledge of motor parameters and possesses fast dynamic response.

\section{REFERENCES}

[1] Jang-Mok Kim and Seung-Ki Sul, "Speed control of interior permanent magnet synchronous motor drive for the flux weakening operation," IEEE Trans. Ind. Appl., vol. 33, no. 1, pp.43-48, Jan/Feb 1997.

[2] Yong-Cheol Kwon, Sungmin Kim and Seung-Ki Sul, "Voltage feedback current control scheme for improved transient performance of permanent magnet synchronous machine drives," IEEE Trans. Ind. Electron., vol. 59, no. 9, pp.3373-3382, Sep 2012.

[3] S. Morimoto, M. Sanda and Y. Y. Takeda, "Wide-speed operation of interior permanent magnet synchronous motors with high-performance current regulator," IEEE Trans. Ind. Appl., vol. 30, no. 4, pp.920-926, Jul/Aug 1994.

[4] S. Morimoto, K. Hatanaka, Y. Tong, Y. Takeda and T. Hirasa, "Servo drive system and control characteristics of salient pole permanent magnet synchronous motor," IEEE Trans. Ind. Appl., vol. 29, no. 2, pp.338-343, May/Apr 1993.

[5] K. Liu and Z. Q. Zhu, "Online estimation of the rotor flux linkage and voltage-source inverter nonlinearity in permanent magnet synchronous machine drives," IEEE Trans. Power Electron., vol.29, no. 1, pp.418-427, Jan 2014.

[6] S. Ichikawa, M. Tomita, S. Doki, and S. Okuma, "Sensorless control of permanent-magnet synchronous motors using online parameter identification based on system identification theory," IEEE Trans. Ind. Electron., vol. 53, no. 2, pp.363-372, Apr 2006.

[7] S. Jung, J. Hong, and K. Nam, "Current minimizing torque control of the IPMSM using Ferrari's method," IEEE Trans. Power Electron., vol. 28, no. 12, pp.5603-5617, Dec 2013.

[8] R. Ni, D. Xu, G. Wang, L. Ding, G. Zhang and L. Qu, "Maximum efficiency per ampere control of permanent-magnet synchronous machines," IEEE Trans. Ind. Electron., vol. 62, no. 4, pp.2135-2143, Apr 2015.

[9] G. Gallegos-Lopez, F. Gunwwan and J. Walters, "Optimum torque control of permanent-magnet ac machines in the field-weakened region," IEEE Trans. Ind. Appl., vol. 41, no. 4. pp.1020-1028, Jul 2005.

[10] Bing Cheng and Tod R. Tesch, "Torque feedforward control technique for permanent-magnet synchronous motors," IEEE Trans. Ind. Electron., vol. 57, no. 3, pp.969-974, Mar 2010.

[11] Samuel J. Underwood and Iqbal Husain, "Online parameter estimation and adaptive control of permanent-magnet synchronous machines," IEEE Trans. Ind. Electron., vol. 57, no.7, pp.2435-2443, Jul 2010.

[12] S. J. Kim, H. W. Lee, K. S. Kim, J. N. Bae, J. B. im, C. J. Kim and J. Lee, "Torque ripple improvement for interior permanent magnet synchronous motor considering parameters with magnetic saturation," IEEE Trans. Magn., vol. 45, no. 10, pp.4720-4723, Oct 2009.

[13] Qian Liu and Kay Hameyre, "High-performance adaptive torque control for an IPMSM with real-time MTPA operation," IEEE Trans Energy Convers., vol. 32, no. 2, pp.571-581, Jun 2017.

[14] Y. R. Mohamed and T. K. Lee, "Adaptive self-tuning mtpa vector controller for IPMSM drive system," IEEE Trans. Ind. Electron., vol. 21, no. 3, pp.636-644, Jan 2006.

[15] M. Azizur Rahman, D. Mahinda Vilathgamuwa, M. Nasir Uddin and King-Jet Tseng, "Nonlinear control of interior permanent-magnet synchronous motor," IEEE Trans. Ind. Appl., vol. 39, no. 2, pp.408-416, Mar/Apr 2003

[16] Garin Schoonhoven and M. Nasir Uddin, "MTPA- and FW-based robust nonlinear speed control of IPMSM drive using lyapunov stability criterion," IEEE Trans. Ind. Appl., vol. 52, no. 5, pp.4365-4374, Sep/Oct 2016.

[17] S. Bolognani, L. Peretti and M. Zigliotto, "Online MTPA control strategy for DTC synchronous-reluctance-motor drives," IEEE Trans. Power Electron., vol. 26, no. 1, pp.20-28, Jan 2011.
[18] S. Bolognani, R. Petrella, A. Prearo and L. Sgarbossa, "Automatic tracking of MTPA trajectory in IPM motor drives based on AC current injection," IEEE Trans. Ind. Appl., vol. 47, no. 1, pp.105-114, Jan 2011.

[19] R. Antonello, M. Carrara and M. Zigliotto, "Theory and implementation of a MTPA tracking controller for anisotropic PM motor drives," in Proc. 38th Аnnu. Conf. IEEE Ind. Electron. Soc., pp.2061-2066, 2012.

[20] Tianfu Sun, Jiabin Wang and Xiao Chen, "Maximum torque per ampere (MTPA) control for interior permanent magnet Synchronous machine drives based on virtual signal injection," IEEE Trans. Power Electron., vol. 30, no.9, pp.5036-5045, Sep 2015.

[21] Tianfu Sun, Jiabin Wang, Mikail Koc and Xiao Chen, "Self-learning MTPA control of interior permanent magnet synchronous machine drives based on virtual signal injection," IEEE Trans. Ind. Appl., vol. 52, no.4, pp.3062-3070, Jul/Aug 2016.

[22] G. Kang, J. Lim, K. Nam, H. B. Ihm and H. G. Kim, "A MTPA control scheme for an IPM synchronous motor considering magnet flux variation caused by temperature," in Proc. IEEE Appl. Power Electron. Conf., pp.1617-1621, 2004. 